\title{
Sosyal Medya Alanına Bourdieucü Bir Yaklaşım: Facebook Üzerine Bir İnceleme
}

\author{
Selver Dikkol (Arş. Gör.) \\ Mersin Üniversitesi İletişim Fakültesi \\ selverdikkol@gmail.com \\ ORCID: 0000-0002-1918-6795
}

Başvuru Tarihi: 17.09.2019

Yayına Kabul Tarihi: 18.11.2019

Yayınlanma Tarihi: 24.01.2020

DOI: http://10.17680/erciyesiletisim.621243

\section{Öz}

Alan ve habitus kavramları başta olmak üzere Bourdieu, özellikle kültürel çalışmalarda işlevsel olan bir teori ortaya koymaktadır. Alan, yapısal bir nitelik taşıyan, belirlenmişliği temsil eden, bireylerin amaçlarını şekillendiren, bütünsel ve ilişkisel bir kavramdır. Habitus ise bireylerin bu alanlar içerisinde nasıl hareket ettiğini çözümleyen bir nosyondur. Kültürel üretim/tüketim pratiklerini sanat, edebiyat ve televizyon gibi geniş ve çok katmanlı alanların analizi yoluyla değerlendiren Bourdieu, 'fail (agent)'olarak kavramsallaştırdığı tüketicilerin habitusuna ve beğeni yargılarına odaklanarak bir kültür kuramı oluşturur. Sosyal medya, gerek üretenleri gerekse kullanıcılarıyla bir bütün olarak ele alındığında, Bourdieu'nün temel kavramlarının özgün biçimde işlediği bir mecrayı işaret eder görünmektedir. Sosyal medya mecraları günümüzde daha çok kullanıcı odaklı bir görünüme sahip olsa da kullanıcılar, kendilerine sunulmuş olan bu alanlarda belli sınırlar içerisinde hareket eder. Bu sınırlar sosyal medya yaratıcılarının imkân ve tahayyülleriyle çizilmektedir. Bu makale, alanın ve habitusun sosyal medya ortamlarında nasıl işlediğini tartışmaktadır. Çalışmada sosyal medya mecralarından birisi olan Facebook alan kavramıyla birlikte çözümlenmektedir. Analiz için otuz Facebook profil sayfası incelenmiş ve elde edilen veriler habitus nosyonu ile birlikte değerlendirilmiştir. Çalışma, sosyal medya araştırmaları için Bourdieu'nün kuramsal çözümlemelerini Facebook ve kullanıcıları üzerinden analiz ederek sosyal medya çalışmaları için halen gelişmekte olan kuramsal ve ampirik araştırma önerilerine bir katkı sunmayı amaçlamaktadır.

Anahtar Kelimeler: Sosyal Medya, Bourdieu, Alan, Habitus, Facebook. 


\title{
A Bourdieuian Approach to Social Media Field: An Analyse on Facebook
}

\author{
Selver Dikkol (Res. Asst.) \\ Mersin University Faculty of Communication \\ selverdikkol@gmail.com \\ ORCID: 0000-0002-1918-6795
}

Date Received: 17.09.2019

Date Accepted: 18.11.2019

Date Published: 24.01.2020

DOI: http://10.17680/erciyesiletisim.621243

\begin{abstract}
Bourdieu, especially with his concepts of field and habitus, has put forward a theory that is particularly functional in cultural studies. The field is a holistic and relational concept that has a structural character, represents determination, and shapes the aims of the agents. Habitus is a notion that analyses how individuals move within these fields. Evaluating cultural production / consumption practices through the analysis of extended and multilayer fields such as art, literature and television, Bourdieu creates a theory of culture by focusing on the habitus and taste judgments of consumers that he conceptualizes as 'agents'. When approached as a whole with its producers and its users, social media seems to indicate a medium in which Bourdieu's basic concepts function in an original way. Although social media channels have a more user-oriented appearance today, users act within certain limits in these areas. These limits are drawn by the possibilities and imaginations of social media creators, and users act within these limits. This article discusses how the theory of field and habitus operates in social media environments. Facebook, which is one of the social media sites, is analysed together with the field concept. Thirty Facebook profile pages were analysed and the data were discussed by the notions of field and habitus. The study aims to contribute to the development of theoretical and empirical research proposals for social media studies by analysing Facebook and users' pages with Bourdieu's theoretical framework.
\end{abstract}

Keywords: Social Media, Bourdieu, Field, Habitus, Facebook. 


\section{Giriş}

Bourdieu'nün pratik kuramı, uzun sayılabilecek bir dönemdir sosyoloji disiplini dışında pek çok farklı akademik alanın da ilgisini çekmektedir. Yapı ve özne arasındaki ikiliği aşmaya odaklı çalışmalarında Bourdieu, toplumsal yapılar ile bu yapılar içerisinde eyleyen failleri ilişkisel olarak ele alır. Çalışmalarında hem teorik hem de saha araştırmalarını birlikte kullanan Bourdieu bu anlamıyla kültürel çalışmalar başta olmak üzere diğer alanlar için de işlevsel bir araştırma seti ortaya koymaktadır. Yeni medya ve sosyal medya çalışmaları da son dönemlerde Bourdieu'nün literatürü ile araştırma yönteminden faydalanmaya başlayan alanlar arasındandır.

Bourdieu'nün bütüncül özellik taşıyan kuramsal seti, medya alanında dijital teknolojilerin yarattığı değişim ve dönüşümleri araştırmak ve çözümlemek adına da sıkça kullanılmaktadır. Örneğin Ignatow ve Robinson (2017), sosyal bilimlerde çalışmalarındaki dijital ve internet temelli teknolojilerin araştırılmasında Bourdieu etkisinin devam ettiğini belirterek, bu etki üzerinden dijital dünyaya bakar. Lindell (2017), alan teorisi ile sosyal medyayı bir araya getirip ağ analizi yöntemini kullanarak Facebook sayfalarını kuramsal açıdan incelemiștir. Benzer bir biçimde Willig ve arkadaşları (2015) alan teorisi ekseninde ele alınan yeni medya araştırmalarını çalışmalarında derlemiştir. Çalışmada, çevrimiçi gündelik yaşamdaki kültürel edimlerden dijital oyunların pratik teorisine, sosyal medya ve akıllı telefon kullanımının habitusundan çevrimiçi kurumsal mecralarda iletişimsel doksanın $(\text { doxa })^{1}$ nasıl işlediğine kadar doğrudan Bourdieu literatürünün kullanıldığı araştırmalardan oluşmaktadır (Willig, Waltrop ve Hartley, 2015, s. 1-12) . Sosyal medya ve internet alanını kültür kuramı ekseninde inceleyen internet ve sosyal medya çözümlemeleri de ayrıca mevcuttur (Herzig, 2016; Setefano, 2016).

Medya olgusu ile Bourdieu'nün kuramsal ve ampirik setinin bir arada kullanıldığı çalışmalar daha yoğun olmakla birlikte (Köse, 2004; Arun, 2010; Köse, 2012; İlic, 2015; Parlak\&Değirmenci, 2015; Karataş, 2019), Türkiye'de Bourdieu'yü sosyal medya ve yeni medyayı ilişkilendiren çalışmalar görece nadirdir. Binark ve Bayraktutan (2011, s. 26), Dijital oyun kültürü haritasında oyuncular: Dijital oyuncuların habitusları ve kariyer türevleri başlıklı kitap bölümlerinde dijital oyuncuların yekpare bir kimliğe bürünmediği aksine çok çeşitli ve farklı yönlere sahip olduğunu, farklı oyuncu türevlerinin sanal uzamda farklı toplumsal, kültürel ve ekonomik sermaye sahipliğinden ötürü farklı oyun oynama edimi sergilediği sonucuna ulaşmışlardır. Dijital ortam ve kültür arasında ilişki kurarak onu sosyal ağlardaki rekabet üzerinden ele alan Güzel (2016) ise "Dijital kültür ve çevrimiçi sosyal ağlarda rekabetin aktörü: Dijital habitus” başlıklı çalışmasında dijital habitusun varlığını sosyal ağlar dolayımıyla analiz etmiştir.

$\mathrm{Bu}$ çalışma da yukarıda bahsedilen araştırmalardan hareketle, Bourdieu'nün alan ve habitus kavramlarını işe koşarak sosyal medyanın sınırlarını ve kullanıcının bu sınırlar içerisindeki failliğini tartışmakta, Bourdieucü perspektif ile sosyal medyayı ele almaktadır. Swartz’a göre Bourdieu, toplumsal dünyayı, aktörlerini ve kategorilerini onları oluşturan daha geniş bir toplumsal ve tarihsel çerçeveye yerleștirerek açıklayan kavramsal bir model inşa eder (Swartz, 2015, s. 46). Bu toplumsal ve tarihsel modelden baktığımızda, sosyal medyanın doğuşunu mümkün kılan şeyin yeni medya teknolojileri olduğu görülür. İletişim alanına doğrudan etkisi olan yeni medya teknolojileri, sosyal medyada kullanıcı türevli içeriklerin üretilmesini, saklanmasını ve yaygınlaştırılmasını sağlayan dijital platformların oluşumunu mümkün kılmıştır. Uzun bir dönemin eşlikçisi olan analog medya araçları (telsiz, telgraf, telefon, radyo ve televizyon), dijitalleşmeye başlayarak, tek bir cihazdan erişilebilir hale gelmiştir. Jenkins, farklı medyaların dijitalleşerek birbiri 
içine geçmesini ve tek bir medya aygıtının fotoğraf çekmek, televizyon izlemek, radyo dinlemek gibi farklı işlevleri yerine getirebilmesini 'convergence (yakınsama) olarak kavramsallaştırır (Jenkins, 2006, s. 10). Dolayısıyla sosyal medyanın, teknolojik iletişim kanallarında yarattığı değişimlere bağlı olarak ortaya çıktığı belirtilebilir.

Çalışmada, sosyal medya mecralarından birisi olan Facebook, çalışmanın ampirik düzlemi için tercih edilmiştir. Bu tercihin birincil nedeni Facebook'un kendisinden önce var olan ve kendisinden sonra ortaya çıkan uygulamalara rağmen her geçen yıl daha fazla kullanıcıya ulaşmasıdır ${ }^{2}$. Yüz yüze ilişkiler kadar önemli bir toplumsal seviyeye ulaşan bu kullanım, pek çok açıdan toplumsal uzamın yeniden ele alınabilmesini de olanaklı kılmaktadır. Facebook'u doğrudan veya dolaylı olarak inceleyen araştırmaların yoğunluğu da bu iletişim pratiğinin göz ardı edilemeyecek bir boyuta ulaştığının göstergelerinden birisidir (Wilson, Gosling \& Graham; Batu \& Yapıcığlu, 2018). Söz konusu sebeplerden ötürü ve kullanıcı ile araç arasındaki ilişkiyi tarihsel yönüyle de ortaya çıkarabilecek potansiyele sahip olduğundan Facebook hem teorik hem de pratik analiz için çalışmada kullanılmaktadır. Çalışmanın temel önermesi, Bourdieu'nün alan ve habitus kavramlarının sosyal medyanın toplumsal ve tarihsel arka planını anlamak için uygun bir araștırma deseni sunabileceğidir. Bu anlamda, Facebook'un nesnel ve pratik nitelikleri bu önermeyi tartışmak adına işe koşulmaktadır.

\section{Alan Nosyonu ve İlişkisel Sosyal Medya}

Bourdieu için toplumsal uzam, kültür, spor, sanat, eğitim gibi çeşitli alanlardan oluşmaktadır. $\mathrm{Bu}$ alanlar içerisinde hareket eden bireyler ise çeşitli bitişiklikler, mücadeleler ve güç ilişkileri içerisindedir. Söz konusu mücadele, alanın yarattığı değerlere sahip olma mücadelesidir ve bu değerler, sermaye olarak adlandırılır. Asgari düzeyde sermayeye sahip olmak, alanda mücadele etme hakkını kazanmaktır ancak öte yandan bu durum sermayeyi artırmak için alandaki diğer faillerle sürekli bir mücadele içinde olmayı da beraberinde getirir. Bourdieu alanın yapısına bağlı olan sermayeleri iktisadi (ekonomik), kültürel, sosyal ve sembolik olarak dört biçimde tanımlar. Sermaye ve alan nosyonlarının birbirine sıkı sıkıya bağlı olduğunu söyleyen Bourdieu, sermayeyi belli bir alanda hem mücadele silahı hem de uğruna mücadele edilen şey olarak tanımlar (Bourdieu, 2014, s. 82). Bourdieu, alan kavramının en iyi, oyun metaforu ile açıklanabileceğini ifade eder: Alan, tarihsel-nesnel bağıntılar bütününden oluşur ve ödüllere inanan, etkin olarak bunların peşinden koşan oyuncular var olduğu ölçüde var olan bir oyun mekânıdır (Bourdieu ve Wacquant, 2014, s. 25-28). Bir oyun için gerekli olan her şey -kurallar, oyuncular, mücadele, katılım, strateji, inanç, sermaye- alanın mantığı için de geçerlidir ve tüm bu olgular ancak ilişkisel biçimde ele alındığında anlamlıdır. Faillerin sermaye için mücadele ettikleri yer olan alan diğer yandan da araştırmacıyı "ortak duyuya dayalı kategorilerde verili olan özellikler yerine, eylemi şekillendiren temel, görünmez ilişkileri aramaya sevk eder." (Swartz, 2013, s. 169). Bourdieu sosyolojisinin aynı zamanda ilişkisel olmasının temel mantığının gerisinde de bu bütüncül yaklaşımın olduğu söylenebilir.

Alanları, yapı/aktör, beden/akıl, öznel/nesnel, birey/toplum, teorik/ampirik gibi ikili karşıtlıklar temelinde çözümlemeyi reddeden bir yaklaşım olan ilişkisellik, süreci odağa alıp değişkenleri birbiri ile ilişkili biçimde çözümlemeyi amaçlar. Crossley, Bourdieucü ilişkisel sosyolojisinin vurguladığı asıl şeyin, zamanın herhangi bir noktasındaki göreli bitişiklikler olduğunu söyler ve bunun kültür, yaşam tarzı ve daha geniş toplumsal eşitsizlik ile tahakküm biçimleri arasındaki etkileșimi araştırmamıza fırsat verdiğini de ekler (2015, s. 2019-210). Bitişiklik, kişileri bir araya getiren olguların neler olduğu sorusunu sormamıza olanak sağladığı için ilişkiselliğin yanı sıra kullanılabilecek işlevsel 
bir nosyondur. Benzer biçimde Swartz da alanların, ilişkisel akıl yürütme tarzına dayanan kavramsal inşalar olduğunu ve araştırmacıyı, eylemi șekillendiren temel, görünmez ilişkileri aramaya sevk ettiğini belirtir (Swartz, 2013, s. 169) .

Yukarıdaki teorik tartışmadan hareketle sosyal medyanın ortaya çıkışını önceleyen tarihsel ve izi sürülebilir nesnel bağıntıların olduğu söylenebilir. Medya tarihi, el yazmalarından, gazete, dergi, fotoğraf, telefon, radyo, sinema ve televizyona uzanan bir serüvene sahipken 1980 sonrasında buna multimedya, yakınsama (convergence), dijitalleşme, sayısallaşma, internet gibi özellikler barındıran yeni medyalar da katılır. El yazmalarından günümüz internet çağına kadar uzanan bu sürecin belirleyici olgusu ise iletişimdir. Yaklaşık altmış yıldır medya, kavramsal olarak iletişim medyası anlamında kullanılmış ve yazılı-sözlü her tür biçimiyle geniş bir skalayı işaret etmiștir (Lister, et all., 2008, s. 9). Sosyal medya da medya ve iletişim arasında hiç kesilmeyen bu bağın ürettiği ortamlardan birisidir. Medya alanının tarihsel süreci içerisinden doğan sosyal medya alanı bu anlamıyla medya ile ilişkili bir konumda yerini almıştır.

Medya ve sosyal medyayı ilişkisel olarak ele almak, her iki olgunun kendine has özelliklerine odaklanmak yerine, onların birbiriyle bağlantılı niteliklerini açığa çıkarma mantığına dayanır. Swartz, toplumsal gerçekliklerin yalnızca diğer gerçekliklerle karşılaştırıldıklarında önem kazandıklarını ve ilişkisel düşünmenin bireylerin ya da grupların içkin özelliklerini aramak yerine ilişkisel niteliklerini inşa etmek anlamına geldiğini belirtir (Swartz, 2015, s. 47-48). Bu uyarı medya ve sosyal medya ekseninde göz önüne alındığında, günümüz sosyal medya mecralarının anlam ve öneminin ancak diğer medyalar ile birlikte anlaşılabileceği gerçeğini işaret eder. Çünkü alanlar arasındaki ilişkiler sabit değil, tarihseldir; alanlar özerkliklerini kaybedebilecekleri gibi koruyabilirler de (Swartz, 2015, s. 60). Örneğin analog medyalar günümüzde çok popüler değillerdir belki fakat şu anki dijital çağın medyası ile benzeşen niteliklere sahiptir. Haber alma, yazılı ve sözlü iletişim, reklam, sansür, merak, eğlence, eğitim ve bilgi gibi analog medyada yer alan ifadelerin benzerleri farklı formlarla sosyal medyada da bulunur. $\mathrm{Bu}$ ilişkisel nitelikler her iki alanın tarihsel bağlantılarından dolayı örtüşmektedir. Zizi Papacarissi 'habitus of the new' kavramı ile sosyal medyanın genelinde oluşan bu durumu açıklamaya çalışır. Yeni medya teknolojileriyle gelişen sosyal medya gibi yeni iletişim biçimleri aslında ritüelleșen pratiklerin yeni bir görünüme bürünmesinden başka bir şey değildir (Papacharissi, Streeter \& Tarleton, 2013, s. 598). Yeni olanın habitusu, sosyal medya alanına yeni ve benzersiz bir yer olarak bakan yaklaşımların karşısına, tarihsel bir arka plan sunmaktadır. Sosyal medyanın bu anlamda, kullanıcılardan bağımsız olarak oluşan ancak kullanıcıların katılımıyla değișen, yenilenen ve farklılaşan bir iletişim biçimi olduğu söylenebilir.

\section{Facebook: Sınırlı Alanda Sınırlı Pratikler}

Facebook, gerek kendi yapısal ve nesnel dinamikleri gerekse kullanıcıları ile birlikte düşünüldüğünde ikili bir düzlemden oluşan sosyal bir ağı betimler. Bu ağ, oyuncudan önce var olan oyun alanı gibidir: Kuralları, sınırları, olanakları ve ödülleri oyun başlamadan önce belirlenen bir alan. Facebook da bir uygulama olarak Mark Zuckerberg tarafından 2004 yllında ve tamamen kendisinin ürettiği bir formatta kullanıma açlır. Harvard Üniversitesi kampüsünden tüm dünyaya doğru yayılan Facebook uygulaması ansızın beliren bir mucizeden ziyade, medya ve yeni medya teknolojilerinin iletişim alanına taşıdığı ekonomik, toplumsal ve politik boyutların tezahürü gibidir. Helmond, Nieborgb ve Vlist, çalışmalarında bu boyutları ele almıştır (Helmond, Nieborgb \& Vlist, 2019, Nieborg \& Helmond, 2019). İnternetin sonsuz gibi görünen uzamında nesnel ve gözlemlenebilir 
bir yer edinen sosyal ağ uygulaması Facebook, bu anlamıyla kullanıcılarına limitsizce eyleyecekleri bir yerden ziyade sınırları önceden belirlenmiş bir alan sunmaktadır (McGoldrick, 2013; Schwarz \& Shani, 2016). 2004 yllından günümüze kadar Facebook, kullanıcılardan, şirketlerden veya kurumlardan gelen geri bildirimler neticesinde ara yüzünü sürekli olarak güncellemektedir. Daha fazla kullanıcının uygulamaya katılımını sağlayabilmek veya var olan kullanıcıları uygulama içinde tutabilmek, özellikle de farklı sosyal ağların ortaya çıkmasıyla birlikte önemli hale gelmiştir. Ancak süreklilik arz eden bu güncellemelere rağmen Facebook uygulaması kullanıcılar için hâlâ pek çok sınırlılık içerir. Dahası, dikkate değer bir oranda Facebook'un hangi amaçlarla nasıl kullanılacağına yönelik rehber niteliğindeki yayınlar, web paylaşımları veya köşe yazılarında görmek mümkündür. Özellikle işlerini yeni kuran kullanıcılar için lansmana yönelik tavsiyeler, Facebook gruplarının etkin kullanımı, iş veya eğitim için ağ oluşturma gibi konular üzerine yoğunlaşan bu rehberler, aynı zamanda kullanım sınırlarına da bir örnek teşkil etmektedir.

Kullanıcıları, ücretsiz olarak üyeliklerini gerçekleştirdikten sonra uygulamanın sunduğu olanaklar dâhilinde Facebook'u kullanmaya başlar. Profil oluşturma, gizlilik ve güvenlik ayarları, arkadaş ekleme, sayfa veya kişi takip etme, gönderi (fotoğraf, video, belge, caps, vs.) paylaşma, paylaşımları beğenme, yorum yapma, anlık fikir paylaşma, yer bildirimi, kişi etiketleme, canlı yayın yapma, mesajlaşma, grup kurma veya var olan gruplara katılma ve hikâye paylaşma gibi olanaklar sunan Facebook, günden güne bu olanakları çeşitlendirmektedir. Bu işlem çeșitliliği, diğer taraftan Facebook'un sınırlarına da işaret eder niteliktedir. Yalnızca kullanıcı olarak siteye iștirak edebilen bireyler, gönüllü bir biçimde bu sinırlarda kalarak devasa bir veri setini uygulama sahibine iletir. Her kullanıcının siteye gömdüğü gerek kişisel gerekse kamusal pek çok bilginin tek sahibi sitenin kurucusu ve çalışanları olur. Gündelik hayatta bu yapısallık kullanıcılar tarafından çok fark edilmese de belli düzenliliklerin ağda oluşmuş olduğu görülür. Bourdieu, önemli oyuncuların davranışlarını ve ifadelerini etnografik olarak gözlemlemeyi ve pratiklerin istatistiksel düzenliliklerini derlemeyi şiddetle tavsiye eder (Swartz, 2015, s. 57). Kullanıcı istatistikleri bu düzenliliğin en önemli göstergelerinden biridir. Türkiye'de ve dünyada internet ve sosyal medya kullanımına yönelik istatistiklere ulaşmak da mümkündür3 .

Üretilmiş, sınırları çizilmiş, belirlenmiş bu alan içinde eyleyen katılımcıların hepsi, Facebook'un sunduğu imkânlar dâhilinde paylaşımlarda bulunabilir. Bu açıdan Facebook, kullanıcılarını belli bir yapı içinde tutar ve yapılandırır. 'Facebook kullanıcısı' terimi bu nedenle yüzergezer bir ifadeyi değil, doğrudan Facebook uygulamasının özellikleriyle tanımlanan bireyi işaret eder.

Facebook, sosyal medya alanında mücadeleye giren ilk aktörlerden birisi olma özelliği taşıdığından, mücadelenin içinde bir fail olarak görülebilir. Alan nosyonu çerçevesinde Facebook'u ele aldığımızda, sınırlar ve sınırlılıklar daha belirgin olacaktır. Alanların varlığı için sermaye sahibi olmak veya onu korumak Swartz'a göre iki biçimde olur: Kaynakları sermayeye dönüştürme mücadelesi ve sermayenin dağılımı üzerine mücadele (2015: 56). Kurucusu Zuckerberg, sahip olduğu eğitim kaynağını sermayeye dönüştürerek alanda bir fail olarak yer almıştır. Günümüzde Facebook, reklam gelirlerinden en fazla para kazanan sosyal ağ şirketidir ${ }^{4}$. Facebook ile sosyal medya alanına giriş yapan Zuckerberg, kaynaklarını ekonomik sermayeye dönüștürebildiğinden ikinci düzey olan sermayenin dağılımı için mücadele alanına girmiştir. Sosyal medya ağları çeşitlendikçe, ortadaki ekonomik sermaye dağılmaya başlamıș, tek bir elde toplanamamıștır. Kendisinden sonra ortaya çlkan YouTube (2005), Twitter (2006), Tumblr (2007), Foursquare (2009), Instagram 
(2010), Snapchat (2012), Periscope (2015) gibi sosyal ağlar, sermayelerin dağılımı için bir mücadele içine girmeye Facebook'u mecbur kılmıştır. Nitekim 2012 yllında Facebook'un kurucusu Instagram’ı satın alarak, bu dağılımdaki yerini belirginleştirmiştir.

Günümüzde Facebook'un da içinde olduğu sosyal medya alanındaki temel mücadele, kullanıcı sayısını artırarak daha fazla reklam geliri elde etme üzerinedir. Kazanılacak bu ekonomik sermaye, ağların yapısını güçlendirmekte, Facebook-Instagram örneğinde olduğu gibi ekonomik kaynakların büyüyüp dağılımında daha fazla pay sahibi olmayı sağlamaktadır. Bourdieu için ise ekonomik sermaye, kültürel, sosyal ve sembolik olarak tanımladığı diğer üç sermayenin ortaya çıkmasını sağlayan temeldir (1986, s. 247). Marx'tan ödünç aldığı 'sermaye' kavramını iktisadi alanla sınırlamayan Bourdieu, farklı türden sermayelerin toplumsal kaynak oluşturduğunu ve her sermaye türünün, maddi olsun olmasın kâr veya verimlilik elde etmeyi amaçlayan bir birikimin ürünü olduğunu belirtir (Jourdain \& Naulin 2016, s. 106). Sonuç olarak bu sermayeler, alanın içerisindeki güç ilişkilerinin yönünü de belirlemektedir. Sermayelere sahip olma hacmine göre Facebook'ta belirli konumları işgal eden aktörler vardır: Facebook şirketinin kendisi, kullanıclar, reklam verenler, veri seti satın alanlar, fenomenler, ünlüler, kurumlar, politikacılar, toplumsal kimlikler ve diğerleri. Bu aktörlerin her biri aslında kendi çıkarlarına göre eyleyen failleridir. Ancak Facebook'u kullanarak doğrudan ekonomik çıkar sağlamak isteyen aktörler dışında kalan kullanıcılar kültürel, sembolik ve sosyal çıkarlar bakımından "ara konumdadırlar" (Swartz, 2015, s. 57). Örneğin kullanıcı, geri bildirim yapıp uygulamadaki kimi özelliklerin güncellenmesine etki edebilir veyahut hassas içeriklerin, lince dayalı paylaşım yapan grup veya kişilerin hesaplarını şikâyet yoluyla kapattırabilmektedir. Bu anlamda kullanıcllar hem üreten (producer) hem de kullanıcı (user) -produser- konumundadır (Bruns, 2009). Bu ara konumun kavranmasına yardımcı olacak bir başka ifade de sosyal medya literatüründen gelir. Baker'ın 'blended identity' (harmanlanmış kimlik) olarak tanımladığı kimlik, söz konusu bileşimi daha açıklar niteliktedir (Baker, 2009). Bu kavrama göre önce çevrimdışı kimlik yeni çevrimiçi kimliği oluşturur. Daha sonra bu yeni çevrimiçi kimlik de çevrimdışı kimliği oradaki diğer kimselerle etkileşim kurabilmesi adına yeniden oluşturur. Kullanıcıların, Facebook hesaplarındaki pratikleri çok çeşitlidir ve bu hesaplar, kültürel, ekonomik, sosyal ve sembolik olarak sahip oldukları varlıklar hakkında bilginin üretildiği mecralardır. Sosyal medya alanında Facebook, Bourdieu'cü anlamda alan etkisini yansıtırken kullanıcılar da Bourdieu'nün habitus nosyonu üzerinden devreye girer. Nihayetinde hiçbir alan farklı sermayeler için mücadele eden failleri olmadan bir alan olarak tanımlanamaz. Bu faillerin alanla kurduğu ilişki ise Bourdieu'nün habitus kavramı ile açıklanır.

\section{Fail Olarak Kullanıcı ve Habitus}

Bireylerin toplumsal uzamdaki tercihlerinin rasyonel bir temeli olduğunu savunan rasyonel seçim teorisine karşı Bourdieu, habitus kavramını geliştirmiștir. Rasyonel seçim teorisine göre birey mantıklı davranarak bir çeşit optimizasyon sürecine girer. $\mathrm{Bu}$ durumda birey her zaman kendisi için optimum kâr sağlayacak olan seçimlere yönelecektir (Coleman \& Fararo, 1992, s. xi). Ancak Bourdieu, mantıklı tercihlerin yanı sıra bireylerin çoğunlukla içerisinde bulunduğu alanın dinamikleriyle de eylemlerinin yönünü belirlediğini belirtir ve bunu habitus ile şöyle tanımlar:

"Habituslar kalıcı yatkınlık sistemleri, yapılandırıcı yapılar şeklinde, yani kurallara itaatin ürünü olmadan, sonuçları bilinçli olarak hedeflenmeden ve bunlara ulaşmak için gerekli işlemlere anında hâkim olmadan ve böylece de bir orkestra şefinin örgütleyici eyleminin ürünü olmadan da kolektif olarak harmoni içinde olabilecek, nesnel olarak 'düzenlenmiş' ve 
'düzenli' olabilecek pratik ve temsillerin üretilme ve yapılandırılma ilkesi olarak işlemeye eğilimli, yapılanmış yapılardır” (Bourdieu, 2018: 158).

Akılcılığın karşısına yatkınlığı, tercihlerin karşısına da nesnel düzenliğini koyan Bourdieu, yukarıda üzerinde durulan ve fail içine girmeden kuralları belli olan -yapılanmışalanlarda faillerin kuralları bilinçdışı olarak takip etme ve yeniden üretme pratiğini habitus olarak görür. Bu yeniden üretim (Bourdieu, 2015a), alanlardaki oyun düzeninin yapılandırılmasını sağlayan eylemliklerin failler tarafından gönüllü biçimde yeniden sağlanmasıdır. Gönüllüğün gerisinde yatan motivasyon ise alanın içerisindeki toplumsal kaynaklar, yani sermayelerdir. Sermaye nosyonu doğrudan iktisadi bir anlama tekabül etse de, prestij, eğitim, statü, sanatsal etkinlikler gibi toplumsal eylemler de birer sermaye olarak işlemektedir (Jourdain \& Naulin, 2016, s. 1106-118). Facebook'un kullanıcı açısından sermayeleri ise bilgisayar destekli araçlara sahip olmak (ekonomik sermaye), sosyal medyayı bu araçlarla birlikte kullanabilmek (kültürel sermaye), sosyal medyada etkileşime girebilecek bir çevreye sahip olmak (sosyal sermaye) ve sosyal medyada görünür olmaktır (sembolik sermaye). Sinırları ve sınırlılıkları kurucusu tarafından belirlenmiş, kuralları konmuş, çizgileri çizilmiş bir mecra olan Facebook’a bu sermayeler açısından bakıldığında buradaki oyuncuların "kurallara itaatin ürünü olmadan, sonuçları bilinçli olarak hedeflenmeden ve bunlara ulaşmak için gerekli işlemlere anında hâkim olmadan" (Bourdieu, 2018, s. 158) kendi çlkarları doğrultusunda sermaye için hareket ettiği söylenebilir. Bu oyuncular, Facebook uygulamasının imkân tanıdığı ölçüde kendi profillerini oluştururlar. Kullanıcılar, katılacağı Facebook grubunu, beğeneceği ve takip edeceği sayfaları ve paylaşımları kendileri tasarlar. Ancak, tüm bu pratikler aslında yapılandırılmış bir yeri yeniden yapılandırmaktan başka bir şey değildir.

\section{Bulgular ve Yorum}

Çalışmada yöntem olarak katılımlı gözlem kullanılmıştır. Araştırmacı kendi Facebook hesabından araştırmaya ilișkin bir çağrı metni paylaşmış ve gönüllü otuz kullanıcı araştırma için kendi profillerinin incelenmesini kabul etmiştir. Araştırma esnasında kullanıcılar, profillerinin bir başkası tarafından bilimsel amaçlı olarak incelendiğinin tamamen bilincindedir. Bu anlamda çalıșma etik açıdan kullanıcıların mahremiyetini gözetmektedir. Gönüllü katılımcıların Facebook sayfaları, etiketleme, durum güncelleme, sayfa beğenileri ve içerik paylaşımı yönünden dört kategoride gözlemlenerek veri toplanmıştır. SPSS ve Cytoscape programları analizi için kullanılırken, Tableu Public programı da görselleştirme için tercih edilmiştir.

\section{Yer Bildirimleri}

Yer bildirimleri de kullanıcıların orada bulunmayı tercih ettiği ve bu tercihi kendi Facebook hesaplarında konum etiketlemesi ile duyurduğu bir pratiktir. Nerede ve kimlerle olduğunu belirtmenin yanı sıra kimi kullanıcılar neler yiyip içtiklerini de görsel olarak ayrıca paylaşmaktadır. Toplumsal uzamda mekânların kendisine ait toplumsal, sınıfsal, ekonomik veya kimi zaman politik bir karşılığı mevcuttur. Fail ve tercihleri arasındaki ilişkinin akılcılığın yanı sıra habitus tarafından da şekillendiği yukarıdaki tartışmalarda ele alınmıştır. Bir beğeni algısı ve yargısına tekabül eden bu yer bildirimleri aynı zamanda kullanıcıların sınıfsal konumlarına yönelik de izler barındırmaktadır. Bu yer bildirimlerinin, söylem ve bilinç düzeyinin altında işleyen ve pratikleri yönlendiren habitusun sonuçlarından birisi olduğu söylenebilir. Böylece yerin temsil ettiği sınıfsallık ile oraya gidenler arasında bir bağın kurulabilmesi mümkündür. Çoğunlukla kullanıcının o yerde bulunmasıyla aynı anda bildirilen yer etiketlemeleri, gerçek ve çevrimiçi uzam arasında bir eş zamanlılık da yaratır. Böylece, fail olarak kullanıcının aslında kendi habitusu 
içerisinde eylerken izlerini sosyal medyaya bıraktığı söylenebilir. Ayrıca mekânlarda çekilen selfie'lerle ve fotoğraflarla verilerin gerçekliği de desteklenebilmektedir. $\mathrm{Bu}$ çalışmada yer alan otuz kullanıcının yer bildirimleri genel olarak aşağıda yer alan figürlerdeki gibidir.

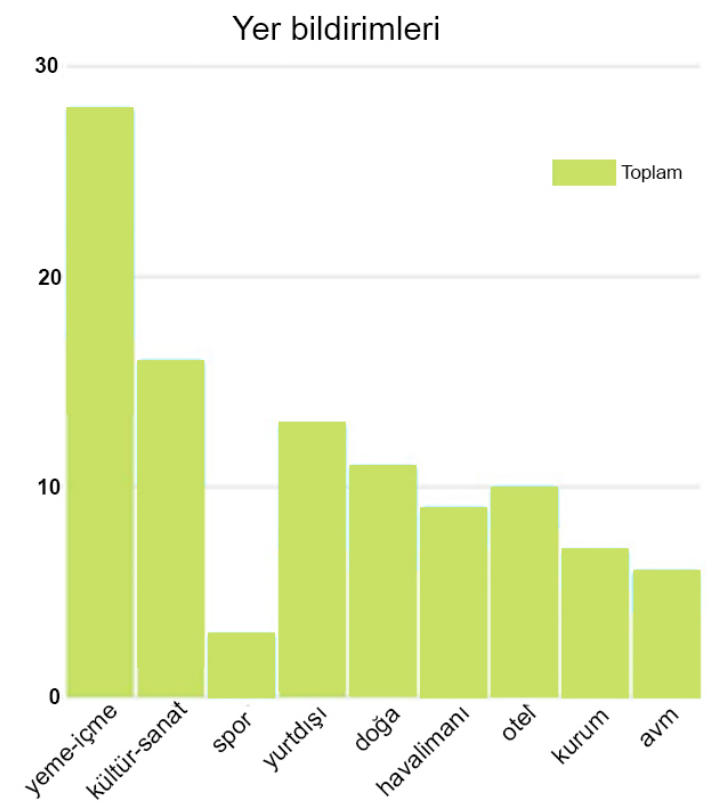

Figür 1: Kullanıcıların yer bildirimleri

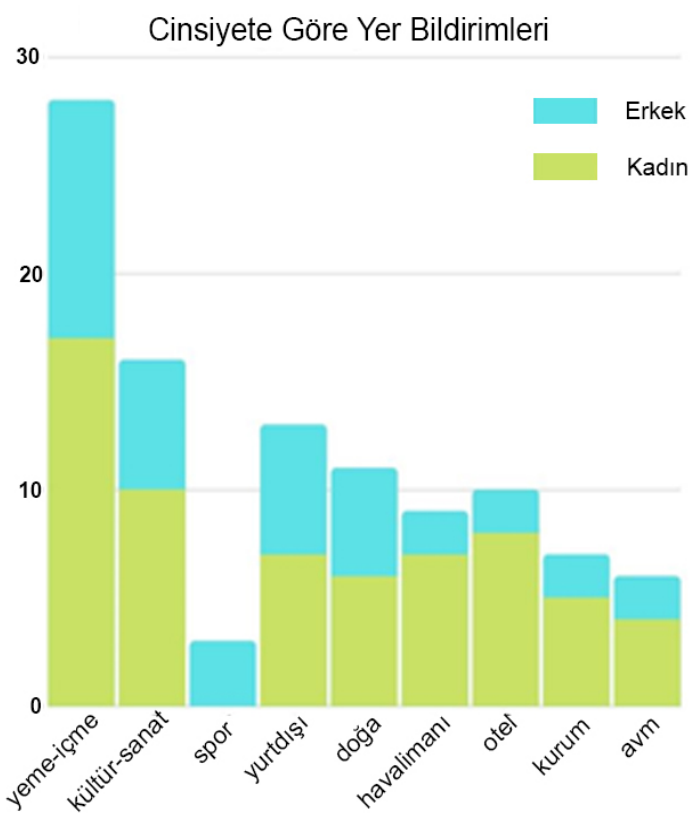

Figür 2: Yer bildirimlerinin cinsiyete göre dağılımı

Kullanıcıların kendilerini çoğunlukla yeme-içme mekânlarında etiketlediği görülmektedir. Bunu, kültür ve sanat mekânlarındaki etiketlemeler takip eder. Yurtdışı veya havalimanı gibi yerlerin belirtilme düzeyi yüksektir. Bu sıklıklar, kullanıcılar için hangi mekânların etiketlenmeye değer olduğu sorusuna da cevap vermektedir. Bildirimler, kullanıcıların sınıfsal ve sosyal konumunu Facebook arkadașlarına iletmenin bu anlamda ișlevsel bir yoludur. Ayrıca, ikinci figürde yer alan oranlar, cinsiyete göre bildirimlerin yoğunluğunu açıklamaktadır. Kadınlar, erkeklere oranla daha fazla yer bildirimi yapıyor görünmektedir. Fakat bu sonucun nedenlerine yönelik açıklamalar için daha çok veriye ihtiyaç vardır. 
Türkiye'de yașayan bireylerin sosyal hayatlarında büyük oranda AVM, kafe ve bar gibi mekânları tercih ediyor olması Facebook'taki yer bildirimlerinde de kendisini göstermektedir. Çalışmaya katılan kullanıcı profillerinde kafe, bar, restoran ve diğer farklı yemekli mekânlar isimleriyle birlikte yer almaktadır. Profillerin gizliliği nedeniyle etik olarak mekân isimlerine burada doğrudan yer verilmemiştir ancak isimlerinden yola çıkarak bu yerlerin karşılık geldiği sınıfsal düzeyi çıkarsamak elbette mümkün olmuştur. Kullanıcıların yer bildirimleri bu anlamda sınıfsal habituslarını yakalayabilmek için olanak sunmaktadır. Ayrıca araștırmacı profil sahiplerinin demografik özelliklerine hakim olduğundan bu yerleri onların sınıfsal konumuyla karşılaștırma imkânı da bulmuştur. Bu anlamda, kullanıcıların sınıfsal konumlarıyla yer bildirimleri çoğunlukla tutarlılık gösterse de kimi yeme-içme mekânlarının sınıfsal temsilleri kültürel bir çeşitlilik göstermiştir. Figür 3'te çalışmaya katılan kullanıcıların yer bildirimleri genel başlıklarla gösterilerek, bu yerlerde kullanıcıların karşılaşma sıklıkları yer almaktadır. Aslında kullanıcılar yaşam tarzı bağlamında genel bir görünüm sergilemesine rağmen, özellikle yeme-içme mekânlarının sınıfsal düzeyi onları ayrıştırmaktadır.

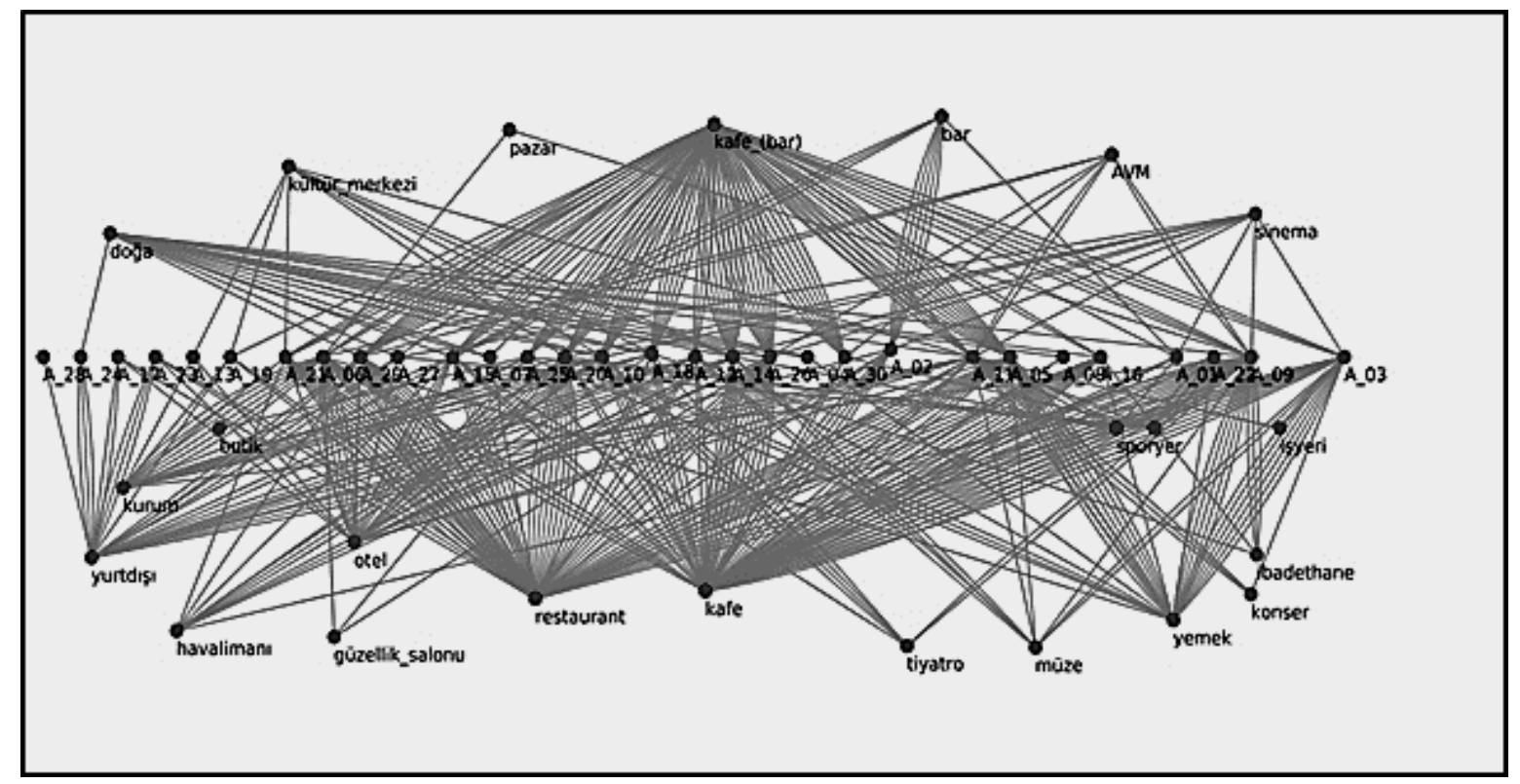

Figür 3: Kullanıcıların yer bildirimlerine göre sosyal ă̆ analizi

Örneğin, aynı kullanıcı hem üst sınıf bir mekânda hem de sanayide yer alan bir köşe başı mekânında kendisini etiketlemiștir. Dahası bu gibi kullanıcılar, ikinci bildirimi yaparken o gün sıra dışı ve alışık olmadığı bir şey yaptığını vurgulayan ifadelere de yer vermiştir. Bir ayrım noktasını vurgulayan bu ifadelerle, kullanıcının 'normal' zamanda gitmeyeceği yerlere gittiğini ancak bunu sıra dişı bir şey olarak meşrulaştırıp sınıfsal ayrıma başvurduğu söylenebilir. Bu nedenle de yer bildirimleri, kullanıcılar arasındaki ayrımları göstermekte ve yeniden üretmektedir. Aynı biçimde çizgi dışına çıkılan durumlar da yine bir ayrım noktası olarak meşrulaştırılarak yeniden üretime dâhil edilmektedir. Bu sembolik ayrımlar, kişisel beğeninin nesnelleşmiş halleridir ve ayırt edici işaretler doğal bir ayrım noktasını imler (Bourdieu, 2015b, s. 413). Uğurlu ve Yakın (2015), sosyal ağlarda mekân etiketlemelerinin sosyal ve sembolik bir kimlik oluşturmadaki rolünü Foursquare örneği üzerinden tartışmıştır. Yazarlar, dijital evrende yer bildiriminin, sanal kültürel kodlar, elektronik olarak ötekiyle ve dünyayla bağ kurma, gerçek hayatla ilişkilendirilen performanslar, mekân üzerinden belirli bir toplumsal sınıfa ait olduğu mesajını verdiği sonuçlarına ulaşmışlardır. 


\section{Paylaşımların İçeriği}

Facebook profilleri, kullanıcıların kendilerine özgü kurduğu dünyanın bir tezahürü gibidir. Profiller çoğu kullanıcının gerçek ismiyle açılsa da rumuz kullanan veya sahte hesaplar açan kullanıcılar da bu mecrada mevcuttur. Ancak, ister gerçek ister aldatmaca olsun, netice itibariyle her profil bir biçimde bireyin yatkınlıklarının izinin sürülebileceği yerlerdir. İzin sürülmesine olanak tanıyan yegâne şey ise kullanıcıların paylaşımları, mecra içerisinde yapıp ettikleridir. Şunu da belirtmek gerekir ki bazı kullanıcıların hesabı atıl durumda da olabilmektedir. Bu tip hesaplar "pusucu" olarak nitelendirilir (Alyanak, 2014, s. 140). Genellikle tanıdık veya tanımadık kimselerin hesabını gözetleme (stalk), gündem takibi, ünlü kişilerin profillerinin takibi ve başka pek çok nedenle pusuya yatan bu kullanıcıların izini sürmek daha zordur. Ancak yine de bu pusucu hesapların beğendiği veya takip ettiği sayfa/kişi profilleri kullanıcı hakkında sınırlı da olsa bir fikir vermektedir. Kullanıcının bu paylaşımları neden seçtiği, neden paylaştığı ve toplumsal uzamın gerçekliği içinde bu paylaşımların nerelere denk düştügü sorularının cevabında habitus vardır. Bourdieu habitus kavramını açıklarken «eyleyicilerin içinde ve dışında var olan toplumsal gerçeklik» ifadesini kullanır; bu, failin kendisini evinde hissetmesi, adeta sudaki bir balık gibi etrafinı doğal algılamasıdır (Bourdieu \& Wacquant, 2014, s. 118-119). Dolayısıyla faillerin 'neden' sorusuna verecekleri yanıtlar eylemlerini meșrulaștırıp doğallaştıran türden olacaktır. Nitekim sosyal medya kullanımı üzerine yapılan pek çok araştırmada bu doğallaştırmayı görmek mümkündür5.

Figür 4'te kullanıcıların toplumsal olaylar karşısındaki duygu ve düşünce paylaşımları (ddp-t), kişisel duygu ve düşünce paylaşımları (ddp-k), gündelik, görsel ve duyuru paylaşımları ve bu paylaşımların sıklıkları yer almaktadır. Kullanıcıların en çok görsel paylaşımları tercih ettiği görülmektedir. Bunu etkileşim amaçlı kullanılan duyuru paylaşımları takip etmektedir. Tahmin edildiğinin aksine kullanıcılar, gündelik hayatı içeren paylaşımları nadiren yapmaktadır. Toplumsal veya kişisel duygu ve düşünce paylaşımlarının sıklığı da düşüktür. Bu durumda kullanıcıların daha çok iletişim ve etkileşim içeren paylaşımlara yöneldiği söylenebilir.

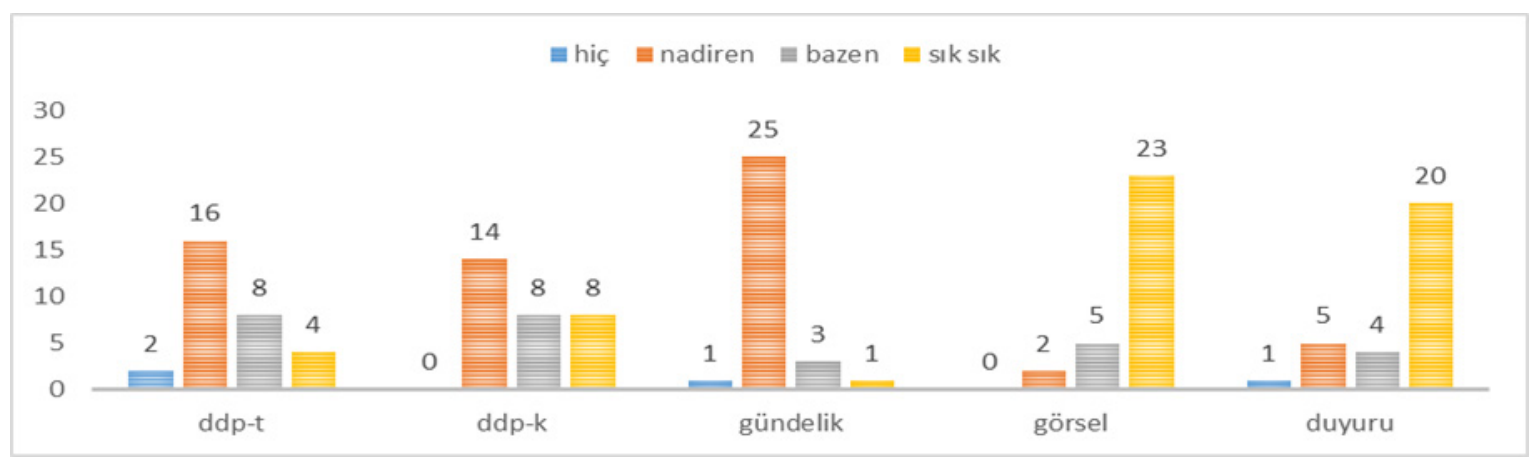

Figür 4: Kullanıcı paylaşımlarının içeriklerine göre sıklıkları

Bu paylaşımların yanı sıra kullanıcılar takip ettikleri sayfaların veya kişilerin içeriklerini de paylaşmaktadır. Paylaşımların her birisi toplumsal uzamın gerçekliğinde bir yere tekabül etmekte ve fail hakkında toplumsal bir tezahür sağlayan eșsiz birer yaşam kombinasyonlarına dönüşmektedir. Habitus kavramı içinde ele alındığında bu kombinasyonlar beğeni yargısını açığa çıkarmakta ve kullanıcının kültürel, ekonomik, sosyal ve sembolik sermayeleri hakkında fikir vermektedir. Yapılandırılmış bir sosyal medya mecrası olan Facebook, kullanıcıları fail düzeyine çekerek bu sermayelerden herhangi birini oluşturmak adına onlara imkân sunmaktadır. Failin kendi kaynaklarını 
alanda işleyen sermayelere dönüştürme ve bu sermayelerin dağılımı üzerinde söz sahibi olma mücadelesi (Swartz, 2015, s. 56) bu anlamda kullanıcılar için de geçerlidir. Toplumsal olaylara ve kişisel tecrübelere yönelik duygu ve düşünce paylaşımları, gündelik hayata dair paylaşımlar, çeşitli multimedya içerikleri ile etkinlik duyuruları gibi Facebook paylaşımlarının incelenen profillerdeki sıklığı da bu mücadele üzerinden okunabilmektedir. Özel hayat paylaşımlarında özellikle evlerin içinde çekilen fotoğraflar, fotoğraflardaki kişilerin kılık kıyafetleri, sofradaki yemekler, içecekler, neyi fotoğrafladığı, karenin içindeki nesneler kullanıcının hem sosyal sermayesi hem de ekonomik sermayesi hakkında bilgiler verir. Bu fotoğraflarda bedene işlemiş yatkınlıklar olarak habitusu görmek mümkündür. Bedenin içinde bulunduğu ortamlarda nasıl davrandığı, hareket ettiği, hissettiğine dair emareler kullanıcıların habitusları hakkında bize bilgi verir.

Facebook paylaşımları yoluyla kullanıcılar, Baker'ın bahsettiği çevrimiçi/çevrimdışı kimlik süreci içerisinde de bulunurlar. Kullanıcılar bir yandan çevrimdışı hayatta olup bitenleri çevrimiçi sayfalarında paylaşırken, benzer biçimde çevrimiçi paylaşımlarını da dişarıya aktarırlar (Dunbar et al. 2015; Chui et al. 2008) Örneğin, duyuru pratiklerinin kullanıcılar tarafından daha çok tercih edilmesi, çevrim içi ve dışı eylemliklerin iç içe geçmesiyle ilgilidir. Kullanıcılar ilgi duydukları veya destek bekledikleri olayların duyurusunu yaparak, çevrimdışı yaşamlarına etki edecek katılımın da yolunu açmaktadır (Grieve et al. 2013; Perez\&Gomez, 2011; Nadkarni\&Hofmann, 2012). Benzer biçimde bu etkinliklere katılanlar ile birlikte kullanıcılar çevrimiçi pratiklere geri dönerler. $\mathrm{Bu}$ karşılıklı ilişki esasen diğer tüm pratikler için de geçerlidir. Kullanıcılar çevrimdışı hayatlarını çevrimiçine taşıyabilir veya tam tersini de yapabilirler. Özellikle spor, kültürsanat, sosyal sorumluluk projelerinde veya yeni toplumsal hareketlerde bu ikili durumun daha sık yaşanması olasıdır.

\section{Beğenilen Sayfalar}

Facebook uygulamasında 'beğen' butonu dışında sayfa beğenileri de mevcuttur. Kullanıcı ilgisine göre seçtiği herhangi bir Facebook sayfasını beğenerek, bu sayfaları takip etmeye başlar. Takip edilen sayfaların tüm paylaşımlarını böylece kullanıcı görebilir. Çalıșmada kullanılan Facebook hesaplarındaki beğenilen sayfalara baktığımızda bunların kategorileştirilemeyecek kadar yoğun olduğu görülür. Dahası beğenilen sayfalar kullanıcılar tarafından sık sık güncellendiği için de ancak belirli bir zaman dilimini kapsayan kesitler halinde paylaşımları ele alınabilmektedir. Kullanıcılar, mizah, spor, sinema, tiyatro, müzik, mekân, edebiyat, televizyon gibi alanlarda açılan sayfaların yanı sıra belirli kurumsal olan veya toplumsal amaçlarla kurulan sayfaları da beğenip takibe almaktadırlar. Beğeni yargısına tekabül eden bu pratik, sosyal bilimlerin aşina olduğu 'tüketim alıșkanlıkları ve yaşam tarzı' olarak sıklıkla ele alınmıştır. Facebook beğenileri de yaşam biçimi anlamında benzer bir veri setini ortaya çıkarabilmektedir. Sayfalar incelendiğinde, kullanıcıların beğeni yargılarına ulaşmak mümkün olmuştur. Beğeniler de tıpkı paylaşımlar gibi kullanıcıların sınıfsal alışkanlıkları ve kültürel sermayeleri ile ilgili bilgi sunmaktadır (Bourdieu, 2015b). Dolayısıyla, eşit imkânlarla uygulama içinde yer alan Facebook kullanıcıları, kendi eylemlikleriyle sınıfsal ve kültürel bir ayrım olușturmaktadırlar. Liu, sosyal ağ sitelerinden birisi olan MySpace'de kullanıcıların ilgi duydukları konular etrafında toplandığını ve kendi beğeni yargılarını performatif bir biçimde oluşturduğunu ifade eder (Liu, 2007). Bu performatiflik, ağda görünmek istediği biçimde kullanıcının kendi profilini habitusuna göre oluşturması olarak da düşünülebilir. Kullanıcıların habitusu, çevrimiçi eylemlerine de taşınmakta ve sermaye mücadelesi burada da devam etmektedir. 


\section{Paylaşımlar, beğeniler, Sembolik ve Sosyal Sermaye}

Bourdieu'nün Türkçeye 'çıkar' olarak da çevrilen illusio (yatırım) nosyonu söz konusu ortaklığın temel nedenini açıklayan bir izlek sunar. Bourdieu'nün deyimiyle failin çıkarı (interresse), oyuna verdiği önem ve değerden başlar. Fail, oyunun oynanmaya değer olduğunu kabul ederek oynamaya başlamakta ve ortaya çıkan hedeflerin izlenmeyi hak ettiğini de böylece kabul etmektedir; kısaca oyunu ve hedefleri kabul eder (1995: 149). Burada atlanmaması gereken önemli bir nokta da oyunun kendisini bir oyun olarak unutturmasıdır. Bu, failin zihinsel yapısı ile toplumsal uzamın nesnelliği arasında kurulan büyülü bir oyun ilişkisidir. İșin büyüsü, bir oyunun oynanmaya değer olup olmadığı sorusunun artık akla bile gelmemesidir; önemli ve ilginç bulduğumuz oyunlar onları böyle düşündüğümüz için değerlidir çünkü bu, oyunun anlamı olarak zihnimize ve bedenimize dayatılmıştır (Bourdieu, 1995, s. 149). Facebook hesapları incelenen kullanıcıların ortak noktası da alana verdikleri bu değerdir. Katılımcılar, Facebook’a bir değer yükledikleri için buraya katılmış ve dolayısıyla mecranın gerisinde yatan alan konumlanmasını -oyunuunutarak eylemeye başlamışlardır ${ }^{6}$. Facebook'un yapısal içeriğine kendisini kaptıran kullanıcılar kamusal veya özel paylaşımlarda bulunmuş, kimi toplumsal olaylara burada tepki göstermiş, ilgi alanına yönelik içerikleri takip ederek beğenmiştir. Kullanıcının kendisini oyuna kaptırma durumu, sosyal medya araştırmalarında daha çok motivasyon kavramı ile birlikte açıklanmaktadır (Ross et al. 2009; Gosling et al. 2011). Motivasyon veya Bourdieucü anlamda çıkar/illusio, sembolik sermaye çerçevesinde fail ilişkiselliğini -başka bir deyişle kullanıcı ve Facebook ilişkisini- açıklayabilmeyi olanaklı kılar.

Yukarıda yer alan tablolar, kullanıcıların birbirilerinden oldukça farklı biçimlerde ve düzeylerde paylaşımlar yaptığını ve içerik beğendiğini göstermektedir. Benzer bir biçimde, kullanıcıların ürettiği içerikler de başkaları tarafından beğenilmekte veya paylaşılmaktadır. Facebook'ta var olmak, tanınmayı, tanımayı, olumlanmayı, takip edilmeyi, beğenmeyi veya beğenilmeyi kapsar. Bunlar, illusio kavramının içerdiği sembolik olarak tanınma ve kabullenme edimleridir (Bourdieu, 1995, s. 185). Facebook ekibi, reklamcilar veya reklam verenler gibi alanda ekonomik sermaye mücadelesi vermeyen kullanıcılar dışındakiler için bu tip kazanımlar simgeseldir (Recuero, 2015). Örneğin yer bildirimleri yoluyla sınıfsal tanınırlık, beğeniler ve paylaşımlar yoluyla da kültürel-estetik tanınırlık hedefinde olunması mümkündür. Bu simgesel var oluş bir yandan statü göstergesiyken diğer yandan da failler arasındaki mücadelenin biçimlerini de belirlemektedir. Ünlü isimlerin, politikacıların veya sosyal medya fenomenlerinin hesaplarında bu sembolik mücadeleyi daha açık görmek mümkündür. Son yıllarda artan ve profesyonelleșen sosyal medya danışmanlığı işi de göstergelerden bir başkasıdır.

Çalışmanın katılımcılarının sembolik sermayeye yönelik ürettiği içeriklerin tahmin edilen izleyici kitlesi (imagined audience) ise onların Facebook arkadaşlarıdır (Murumaa\&Siibak, 2012; Litt\&Hargittai, 2016). Her kullanıcının bildirim, paylaşım ve beğenilerini görenler ve izleyenler diğer kullanıcılardır, yani Facebook arkadaşlarıdır. Dolayısıyla sembolik sermayenin üretildiği bu içerikler aynı zamanda sosyal sermayenin de dolaşıma girdiği yerlerdir. Sosyal sermaye, birbiriyle tanışma ve karşılıklı tanımaya dayalı olan bir ağın mensuplarının birbirlerinin sermayelerinden vekâleten faydalanmalarıdır (Jourdien\&Naulin, 2016, s. 107). Kullanıcıların sosyal ağındaki Facebook arkadaşlarının kültürel ve iktisadi sermayelerinin büyüklügüne bağlı olarak kullanıcıların sosyal sermayelerinin yoğunluğu değişmektedir (Julien, 2015). Örneğin, çalışmaya katılan kullanıcıların Facebook çevresi, kendisi gibi veya çoğunlukla kendisinden daha üst konumlarda yer alan arkadaşlardan oluşur. Bu anlamda Facebook'ta 'arkadaşlık' sosyal 
sermayenin işlediği bir pratik olarak ele alınabilmektedir (Ellison et al. 2007; Ellison et al. 2007; Kwon et al. 2013).

\section{Sonuç}

Yeni medya teknolojileri ile birlikte gelişen sosyal medya alanı, kendisinden önce ve sonraki iletişim biçimleriyle ilişkili olarak kişilerin gündelik hayatında yer almıştır. 'Yeni' olarak nitelenen bu iletişim biçimi ise esasen tarihsel bir sürece sahiptir. Yoktan var olmayan sosyal medya, önceki medya araçlarının yakınsamasıyla daha kompakt bir hal almış, bu da hızlı, etkileşimli ve hiper-metinsel bir iletişim biçiminin oluşmasını sağlamıștır. Sosyal medya, bu iletişim biçimlerinin en yoğun kullanıldığı alanlardan birisidir. İçerdiği tarihsel ve ilişkisel kullanım pratikleri sosyal medyayı Bourdieucü bir bakış açısıyla ele almayı da olanaklı kılmıştır.

Çalışmada, otuz Facebook profili analiz edilerek Bourdieu'nün alan ve habitus kavramları çerçevesinde ele alınmıştır. Profillerdeki yer bildirimleri, paylaşımlar ve beğeniler odağında gerçekleşen bu analizde, kullanıcıların kendi habituslarına paralel olarak izlerini Facebook hesaplarına bıraktığı görülmüştür. Özellikle yer bildirimleri ve beğeniler, sınıfsal çıkarımlar yapmanın ve kullanıcılar arasındaki ayrım noktalarını belirlemenin önemli bir aracı olmuştur. Kullanıcıların nerede ne yaptıklarını ilettikleri bu yer bildirimleri, mekân isimlerinin tekabül ettiği sınıfsal pratikle birlikte okunabilmektedir. Bu anlamda kullanıcılar, yer bildirimleri ile sınıfsal konumlarını ișaret ederek, habituslarına göndermeler yapmaktadır.

İncelene profillerdeki paylaşım ve beğeniler, kullanıcıların kültürel, sembolik ve sosyal sermayelerine dair bilgiler içermektedir. Profillerin içeriklerinde yer alan bu pratikler, kullanıcıların aslında birer fail olarak kendi ortamlarında eylediklerini, bunu yaparken de söz konusu sermayeleri işlettiğini göstermektedir. Sınırları belli bir sosyal medya alanında failler, konumlarını bu sınırlar içinde tutmaktadır. Beğeni, paylaşım veya yer bildirimleri ile konum alan bu failler, diğer kullanıcılardan kendilerini farklılaştıran içerikler üreterek ayrım noktaları belirlemektedir. Habituslarından kaynaklı bu ayrım noktaları çevrimiçi ve çevrimdıșı evrenin ilişkisel yönüne de vurgu yapmaktadır. Bu anlamda, Bourdieucü bir yaklașımla sosyal medyayı ele almak bütünsel bir bakış açısıyla ilişkileri değerlendirmeyi olanaklı kılmıştır.

\section{Notlar}

1 Doksalar, toplumsal bir dünya, bir varsayımlar evrenidir; toplumsal dünyanın verili doğal bir dünya olarak algılanmasını sağlar (Bourdieu, 2014, s. 201). Doksa kavramı, bilinçdışı ideolojik nosyonları işaret eder (Etil \& Demir, 2014, s. 343).

2 Daha ayrıntılı bilgi için bkz. https://www.slideshare.net/slideshow/embed_code/key/NSBCWzcfsbGXTg (Erişim 18 Ekim 2019).

3 Bu istatistikler kullanıcıların düzenlilikleri hakkında genel anlamda bir bilginin biriktiği kaynaklardır. Bkz:

(1) http://tuik.gov.tr/PreTablo.do?alt_id=1028.; (2) https://www.medyaakademi.org/2018/07/31/turkiyede-genclerinsosyal-medya-kullanim-aliskanliklari-arastirma-raporu/; (3) https://wearesocial.com/

4 https://datareportal.com/reports/digital-2019-global-digital-overview

5 Türkiye ve dünya literatürüne baktığımızda kullanım nedenlerinin çok çeşitli olduğu görülse de iki temel saik ön plana çıkmaktadır: kullanım ve servis sağlayıcıları. Kullanım daha çok eğlence, sosyalleşme, iletişim ağını güncelleme gibi amaçları içermektedir. Kullanıcılar servis sağlayıcıların güvenli ve gizliliğe önem verdiğini, kişisel veya gruplar arası bilgi paylaşımında işlevsel ve hızlı olduğunu da belirtmişlerdir (Perez \& Gomez, 2011: 46-47).

6 Alan konumu ile burada kastedilen şey, Facebook'un daha önceki sayfalarda ele alınıp tartışılan hâkim konumudur. Facebook, sermayeleri bakımından ele alındığında bir sosyal medya alanıdır ve aktörler arasında çeşitli mücadelelere sahne olur. 


\section{Kaynakça}

Arun, Ö. (2010). Türkiye' de televizyon alanının sosyal yapısı ve televizyon alanında kültürel tüketim pratikleri Doktora Tezi, Selçuk Üniversitesi, Sosyal Bilimleri Enstitüsü.

Baker, A. J. (2009). Mick or Keith: blended identity of online rock fans. Identity in the Information Society, 2(1), 7-21.

Batu, M.\&Yapıcıoğlu Ayaz, Y. (2018). Bilimsel araştırmalarda sosyal medya ile ilgili "yeniyi” bulmak: Lisansüstü tezlerine yönelik bir inceleme. Akdeniz Üniversitesi İletişim Fakültesi Dergisi. 29, 284-301.

Binark, M. \& Bayraktutan, G. (2011). Dijital oyun kültürü haritasında oyuncular: dijital oyuncuların habitusları ve kariyer türevleri. A. T. Aydemir (Ed.), Katılımın "e-hali": Gençlerin Sanal Alemi (s. 303-330) içinde. İstanbul: Alternatif Bilişim.

Alyanak, B. Z. (2014). Etnografi ve çevrimiçi etnografi. M. Binark (Ed.). Yeni Medya Çalışmalarında Araştırma Yöntem ve Teknikleri (s. 117- 163) içinde. İstanbul: Ayrintl.

Bourdieu, P. (1986). The forms of capital. J. G. Richardson (Ed.). Handbook of Theory and Research for the Sociology of Education (s. 241-258) içinde. New York, Westport, Connecticut \& London: Greenwood Press.

Bourdieu, P. (1995). Pratik nedenler. (H. Tufan, Çev.). İstanbul: Kesit.

Bourdieu, P.\&Wacquant, L. (2014). Düşünümsel bir antropoloji için cevaplar. (N. Ökten, Çev.). İstanbul: İletişim.

Bourdieu, P. (2014). Simgesel sermaye ve toplumsal sınıflar. (E. Ünal, Çev.). G. Çeğin, E. Göker\&N. Ökten (Eds.). Cogito: Pierre Bourdieu (s. 192-203). İstanbul: YKY.

Bourdieu, P. (2015a). Yeniden üretim. (L. Ünsaldı, A. Sümer \& Ö. Akkaya, Çev.). Ankara: Heretik.

Bourdieu, P. (2015b). Ayrım: Beğeni yargısının toplumsal eleștirisi. (D. Fırat Şannan\&G. Berkkurt, Çev.). Ankara: Heretik.

Bourdieu, P. (2018). Bir pratik teorisi için taslak: Kabiliyet üzerine üç etnoloji çalışması. (N. Ökten, Çev.) İstanbul: İstanbul Bilgi Üniversitesi.

Bruns, A. (2009). From prosumer to produser: understanding user-led content creation. Transforming Audiences, 3-4 Sep, 2009, London.

Chiu, P. Y., Cheung, C. M.,\&Lee, M. K. (2008). Online social networks: Why do "we" use Facebook? World Summit on Knowledge Society (s. 67-74) içinde. Berlin: Springer.

Coleman, J. S.,\&Fararo, T. J. (1992). Rational choice theory. California: Sage.

Di Stefano, A. (2016). Weak (cultural) field: A Bourdieuian approach to social media. G. Austin (Ed.) New Uses of Bourdieu in Film and Media Studies (s. 141-162) içinde. New York-Oxford: Berghahn.

Dunbar, R. I. M., Arnaboldi, V., Conti, M.\&Passarella, A. (2015). The structure of online social networks mirrors those in the offline world. Social Networks, 43, 39-47.

Ellison, N., Steinfield, C.,\&Lampe, C. (2006). Spatially bounded online social networks and social capital. International Communication Association, 36, 1-37. 
Ellison, N. B., Steinfield, C.,\&Lampe, C. (2007). The benefits of Facebook "friends:" Social capital and college students' use of online social network sites. Journal of computermediated communication, 12(4), 1143-1168.

Etil, H.\&Demir, M. (2014). Pierre Bourdieu'nün bilim sosyolojisine katkısi: Alan teorisi, habitus cini ve refleksivite talebi. G. Çeğin, E. Göker\&N. Ökten (Eds.) Cogito: Pierre Bourdieu (s. 311-349). İstanbul: YKY.

Gosling, S. D., Augustine, A. A., Vazire, S., Holtzman, N., \&Gaddis, S. (2011). Manifestations of personality in online social networks: Self-reported facebook-related behaviors and observable profile information. Cyberpsychology, Behavior, and Social Networking, 14(9), 483-488.

Grieve, R., Indian, M., Witteveen, K., Tolan, G.A. \&Marrington, J. (2013). Face-to-face or Facebook: Can social connectedness be derived online? Computers in Human Behavior 29(3), 604-609.

Güzel, E. (2016). Dijital kültür ve çevrimiçi sosyal ağlarda rekabetin aktörü: "dijital habitus". E- GIFDER, 4 (1), 82-103.

Helmond, A., Nieborgb, D. B.\&van der Vlist, F. N. (2019). Facebook's evolution: development of a platform-as infrastructure. Internet Histories, 3 (2), 123-146.

Herzig, R. (2016). A Bourdieuian approach to internet studies: Rethinking digital practice. G. Austin (Ed.) New Uses of Bourdieu in Film and Media Studies (s. 107-123) içinde. New York-Oxford: Berghahn.

Ignatow, G.\&Robinson, L. (2017). Pierre Bourdieu: Theorizing the digital. Information, Communication\&Society, 20 (7), 950-966.

İlic, D.T. (2015). Pierre Bourdieu ve televizyon alanı: Türkiye'deki ana akım televizyon haberciliğinde bir saha araştırması. Selçuk Üniversitesi İletişim Fakültesi Akademik Dergisi, (8) 4, 321-340.

Jourdain, A.\&Naulin, S. (2016). Pierre Bourdieu'nün kuramı ve sosyolojik kullanımları. (Ö. Elitez, Çev.). İstanbul: İletişim.

Julien, C. (2015). Bourdieu, social capital and online interaction. Sociology, 49(2), 356-373.

Karataș, E. (2019). Medyada kanaatler üzerine: Kanaat üreticileri doksozoflar. Üsküdar Üniversitesi İletişim Fakültesi Akademik Dergisi Etkileşim, 4, 254-275.

Köse, H. (2004). Bourdieu medyaya karşı / Medya: İşbirlikçi, Zorba ve çığırtkan. İstanbul: Papirüs.

Köse, H. (2012). Bourdieu'cü beğeni yargısı açısından izleyici ve medya. İstanbul Üniversitesi İletişim Fakültesi Dergisi, 15, 271-284.

Kwon, M. W., D’Angelo, J.,\&McLeod, D. M. (2013). Facebook use and social capital: To bond, to bridge, or to escape. Bulletin of Science, Technology\&Society, 33(1-2), 35-43.

Litt, E.\&Hargittai, E. (2016). The imagined audience on social network sites. Social Media+ Society, 2(1), 1-12.

Liu, H. (2007). Social network profiles as taste performances. Journal of Computer-Mediated Communication, 13(1), 252-275.

McGoldrick, D. (2013). The limits of freedom of expression on Facebook and social networking sites: A UK perspective. Human Rights Law Review, 13(1), 125-151. 
Murumaa, M.\&Siibak, A. (2012). The imagined audience on Facebook: Analysis of Estonian teen sketches about typical Facebook users. First Monday, 17(2). https://doi. org/10.5210/fm.v17i2.3712.

Nadkarni, A.\&Hofmann, G. S. (2012). Why do people use facebook? Personality and Individual Differences, 52(3), 243-249.

Nieborg, D. B.\&Helmond, A. (2019). The political economy of Facebook's platformization in the mobile ecosystem: Facebook Messenger as a platform instance. Media, Culture\&Society, 41(2), 196-218.

Parlak, İ.\& Değirmenci, N. (2015). Zaman gazetesi köşe yazarlarının bir rol değişim göstergesi olarak Bourdieucü bağlamda söylemsel dönüşümleri (2011'den 2014'e). İleti-ş-im Dergisi, 23, 9-38.

Papacharissi, Z., Streeter, T. \&Gillespie, T. (2013). Culture Digitally: Habitus of the New. Journal of Broadcasting\&Electronic Media, 57 (4), 596-607.

Perez, M.\&Gomez, J. M. (2011). Why do people use social networks? Communications of the IIMA, 11(2), 41-50.

Recuero, R. (2015). Social media and symbolic violence. Social Media+ Society, 1(1), 1-3.

Ross, C., Orr, E. S., Sisic, M., Arseneault, J. M., Simmering, M. G.\&Orr, R. R. (2009). Personality and motivations associated with Facebook use. Computers in Human Behavior, 25 (2), 578-586.

Schwarz, 0.\&Shani, G. (2016). Culture in mediated interaction: Political defriending on Facebook and the limits of networked individualism. American Journal of Cultural Sociology, 4(3), 385-421.

Swartz, D.L. (2015). Bourdieucü perspektiften sosyolojik analiz için meta-ilkeler. (P. Gorski (Ed.), içinde Bourdieu ve Tarihsel Analiz. Ankara: Heretik.

Uğurlu, Ö.\&Yakın, M. (2015). Sosyal medyada kimlik temsilinin mekân üzerinden okunması: Foursquare. Ö. Oğuzhan (Ed.) İletişimde Sosyal Medya-Sosyal Medyada İletişim (s. 199-240) içinde. İstanbul: Kalkedon.

Wilson, R.E., Gosling, S. D.\&Graham, L.T. (2012). A review of facebook research in the social sciences. Perspectives on Psychological Science, 7(3), 203-220. 


\title{
A Bourdieuian Approach to Social Media Field: An Analyse on Facebook
}

\author{
Selver Dikkol (Res. Asst.)
}

\section{Extended Abstract}

Bourdieu, especially with his concepts of field and habitus, has put forward a theory that is particularly functional in cultural studies. The field is a holistic and relational concept that has a structural character, represents determination, and shapes the aims of the agents. For Bourdieu, social space consists of various fields such as culture, sports, art, and education. The space is comprised of a collection of historical-objective relationships, and it is a playground that its existence depends on the players who believe in rewards and actively pursue them (Bourdieu and Wacquant, 2014, s. 25-28). The agents who move within these areas are in various contiguities, struggles and power relations. The struggle is to have the values created by the field and these values are called as capital. The capitals which depend on the structure of the field have four forms: economic, cultural, social and symbolic. Bourdieu discusses that the notions of capital and space are closely interdependent and he defines the capital as both a weapon of struggle and a thing which is struggled for (Bourdieu, 2014, s. 82). The field where agents struggle for capital, on the other hand, urges the researcher to look for basic, invisible relationships that shape action, rather than traits given in common sense categories (Swartz, 2013, s. 169). This holistic approach is behind the basic logic of Bourdieu's sociology to be relational at the same time. Relationalism, which is an approach that refuses to analyse the areas on the basis of dual contradictions such as structure/actor, body/mind, subjective/objective, individual/society, theoretical/empirical, aims to analyse the variables in relation to each other by focusing on the process.

When approached as a whole with its producers and its users, social media seems to indicate a medium in which Bourdieu's basic concepts function in an original way. Although social media channels have a more user-oriented appearance today, users act within certain limits in these areas. These limits are drawn by the possibilities and imaginations of social media creators, and users act within these limits. Facebook is one of these social media consisting of a dual plane with its own structural and objective dynamics as well as with users. This network is a playground that existed before the players: a field where rules, limits, possibilities and rewards are set before the start of the game. Since it has the potential to reveal the relationship between the user and the medium with its historical aspect, Facebook is used in the study for both theoretical and practical analysis. Since it has the potential to reveal the relationship between the user and the tool with its historical aspect, Facebook is used in the study for both theoretical and practical analysis. In the study, where objective and practical qualities of Facebook are employed, social media is analysed with the concept of 'space', and user actions are analysed with the concept of 'habitus'.

In this study, data obtained from thirty Facebook profiles through participant observation are used. The researcher shared a post from her private Facebook account, and thirty volunteer users agreed that their Facebook profiles could be used for the research. During the research, users are fully aware that their profiles have been observed by someone else for scientific purposes. Facebook pages of volunteer participants were observed in 
four categories: place tagging, status update, page likes and content sharing. SPSS and Cytoscape programs were used for analysis, while Tableau Public program was preferred for visualization.

In the user profiles participating in the study, cafes, bars, restaurants and different places are included with their names. It is possible to deduce the class level of these places by their names. Therefore, place tagging shows a reproduction of the distinctions between users. These symbolic distinctions are objectified states of personal taste, and distinctive signs mark a natural point of distinction (Bourdieu, 2015b, s. 413). While these places tagging are related to distinction, the shares of users point to habitus. Shares about private life, shares of the pages or people followed, multimedia shares, instant emotion thoughts, space shares correspond to a place in the reality of social space. Taken within the concept of habitus, these combinations reveal the judgment of taste and give an idea about the user's cultural, economic, social and symbolic capitals. Therefore, these contents where symbolic capital is produced are also places where social capital enters the circulation. When we look at the likes of the pages in areas such as humour, sports, cinema, theatre, music, space, literature, television, users, we reached that the users' habitus is also being carried on to their online actions and the capital struggle continues also here.

As a result, Facebook, which is one of the social media tools, has information about class separation, symbolic and social capital when taken together with Bourdieu's concepts of space and habitus.

Keywords: Social Media, Bourdieu, Field, Habitus, Facebook. 
